\title{
Bond Strength of Permanent Cements in Cementing Cast to Crown Different Core Build-up Materials
}

\author{
Yusuf Ziya BAYINDIR ${ }^{1}$, Funda BAYINDIR ${ }^{2}$ and M. Samil AKYIL ${ }^{2}$ \\ ${ }^{1}$ Conservative Dentistry Department \\ ${ }^{2}$ Prosthodontics Department School of Dentistry, Atatürk University, 25240-Erzurum, Turkey \\ Corresponding author, E-mail:ybayy@atauni.edu.tr
}

Received December 17, 2003/Accepted March 19, 2004

\begin{abstract}
The purpose of this laboratory investigation was to evaluate the bond strength of permanent cement (Duo-cement Kit, Meron, Durelon) to commonly used core build-up materials (President, Dyract AP, Ionofil, Vitremer).

Sixty specimens (five of each product) were fabricated as a canine core build- up. Full crown castings were made to fit each core specimen. Full crown castings were cemented to core samples and stored at $37^{\circ} \mathrm{C}$ and $100 \%$ humidity for 10 days. After storage, the bond strength was measured with a Haunsfield tensometer in tensile mode at a crosshead speed of $5 \mathrm{~mm} /$ $\min$.

Statistical evaluation was performed with univariate analysis of variance $(\mathrm{P}<0.001)$. The cement types affected the bond strength of full crown castings to core materials $(\mathrm{F}: 14.80 ; \mathrm{P}<0.001)$. The interaction between the cement and core materials was significant $(\mathrm{F}: 3.69$; $\mathrm{P}<0.01)$. According to the Duncan's test it was found that the values of Duo-cement were statistically different from the other cements.
\end{abstract}

Key words: Permanent cements, Core materials, Bond strength

\section{INTRODUCTION}

Endodontically treated teeth often require a post and core before they can be restored with a crown ${ }^{1,2)}$. Various materials are used in restorative dentistry to make pin and post retained cores. Casting alloys, silver amalgam, resin composite, glass ionomer, resin modified glass ionomer, porcelain, compomer are most frequently used for cores on fractured or devitalised teeth.

Important factors related to the success of a cast restoration are the design and quality of tooth or core and the accuracy of the casting. Other factors that contribute to longevity and success include 1) the type of core material to which the casting is cemented 2) the biophysical characteristics of the luting medium and 3) the degree of bond strength between the cement and core materials ${ }^{1,3)}$.

The bond strength of a luting agent to dentin is an important consideration in the success of the cast restorations. It is equally important that the bond strength of luting agents to various core materials be within the range of clinical acceptability ${ }^{4)}$.

This in vitro study was conducted to compare the bond strength of three luting agents to four different commonly used core build-up materials.

\section{MATERIALS AND METHOD}

Table 1 and 2 show the cement and core materials used in this study. A maxillary canine tooth was prepared as a core form (uniform space area and a 7 - degree taper) and this sample was used as a master model. Using this master model a mould was prepared with elastomeric impression material (Speedex putty and light bady, Coltene, Altstatten, Sweden). The mould was filled with Dynamic universal composite resin (President, Dynamic Universal Hybrid Composite Munchen, Germany) to produce a total of 60 cores. Co-Cr (Wironit, Bego, Bremen, Germany, Co: 64.0 , Cr: 28.65 , Mo: 5.0, C: $\max .0 .35$, Si, Mn: 0.5) full crown castings were made to fit the 60 cores. A simple wax pattern with a loop was attached to the occlusal surface of crowns. The cast samples were produced by the lost-wax technique in a centrifugal, induction-heated casting machine (Rotaks Dental, Beyoglu/Istanbul) according to the manufacturers' direction. The crowns were cleared of all traces of polish disclosing wax using an ultrasonic bath.

Die space solution (Rem-e-die, Ivoclar vivadent, Shaan, Liechtenstein) was used to increase the size of the die at a controlled amount. The cements' space was approximately $25 \mu \mathrm{m}$. Each luting agent was applied to the full crowns $(n=5)$ for each core material. All cements were mixed by following the man ufacturer's instructions and applied to the cores. The crowns were seated quickly and pressed with firm finger pressure by continuous force to extrude all the excess cement from the margins. The pressure was maintained until the cement was set. Excess cement was also left until the set was complete and it was then removed. After full crown castings were cemented to the cores, samples were stored at $37^{\circ} \mathrm{C}$ and $100 \%$ humidity for 10 days. 
Table 1 Core materials that were used in this study

\begin{tabular}{lll}
\hline \multicolumn{1}{c}{ Core materials } & Brand name & \multicolumn{1}{c}{ Manufacturer } \\
\hline Hybrid Composite & President & $\begin{array}{l}\text { Lightcure Dynamic Universal Composite } \\
\text { München, Germany }\end{array}$ \\
\hline Glass-ionomer & Ionofil & Voco, Cuxhaven/Germany \\
\hline $\begin{array}{l}\text { Resin modified } \\
\text { Glass-ionomer } \\
\text { Cement (RMGIC) }\end{array}$ & Vitremer & 3M Dental Products, St. Paul MN, USA \\
\hline Compomer & Dyract AP & Dentsply DeTrey D-78467 Konstanz, Germany \\
\hline
\end{tabular}

Table 2 Luting cements that were used in this study

\begin{tabular}{lll}
\hline \multicolumn{1}{c}{ Brand name } & \multicolumn{1}{c}{ Type } & \multicolumn{1}{c}{ Manufacturer } \\
\hline Durelon & Carboxylate cement & ESPE, Secfield, Germany \\
\hline Duo-cement Kit & Resin cement & Coltene, Switzerland \\
\hline Meron & Glass ionomer cement & Voco, Cuxhaven/Germany \\
\hline
\end{tabular}

Table 3 Duncan's test results for luting cement

\begin{tabular}{lccc}
\hline \multirow{2}{*}{ Cement } & N & \multicolumn{2}{c}{ Subset } \\
\cline { 3 - 4 } & & 1 & 2 \\
\hline Meron & 20 & $\mathrm{a} 8.90$ & \\
Durelon & 20 & $\mathrm{a} 9.00$ & \\
DuoCement & 20 & & $\mathrm{~b} 16.35$ \\
Sig. & & 0.949 & 1.000 \\
\hline
\end{tabular}

Table 4 Duncan's test results for core materials

\begin{tabular}{lcccc}
\hline \multirow{2}{*}{ Cement } & N & \multicolumn{3}{c}{ Subset } \\
\cline { 3 - 5 } & & 1 & 2 & 3 \\
\hline Compomer & 15 & $\mathrm{a} 6.20$ & & \\
Composite & 15 & $\mathrm{ab} 9.80$ & $\mathrm{ab9.80}$ & \\
Glass ionomer & 15 & & $\mathrm{~b} 10.80$ & \\
RMGIC & 15 & & & $\mathrm{c} 18.87$ \\
Sig. & & 0.053 & 0.584 & 1.000 \\
\hline
\end{tabular}

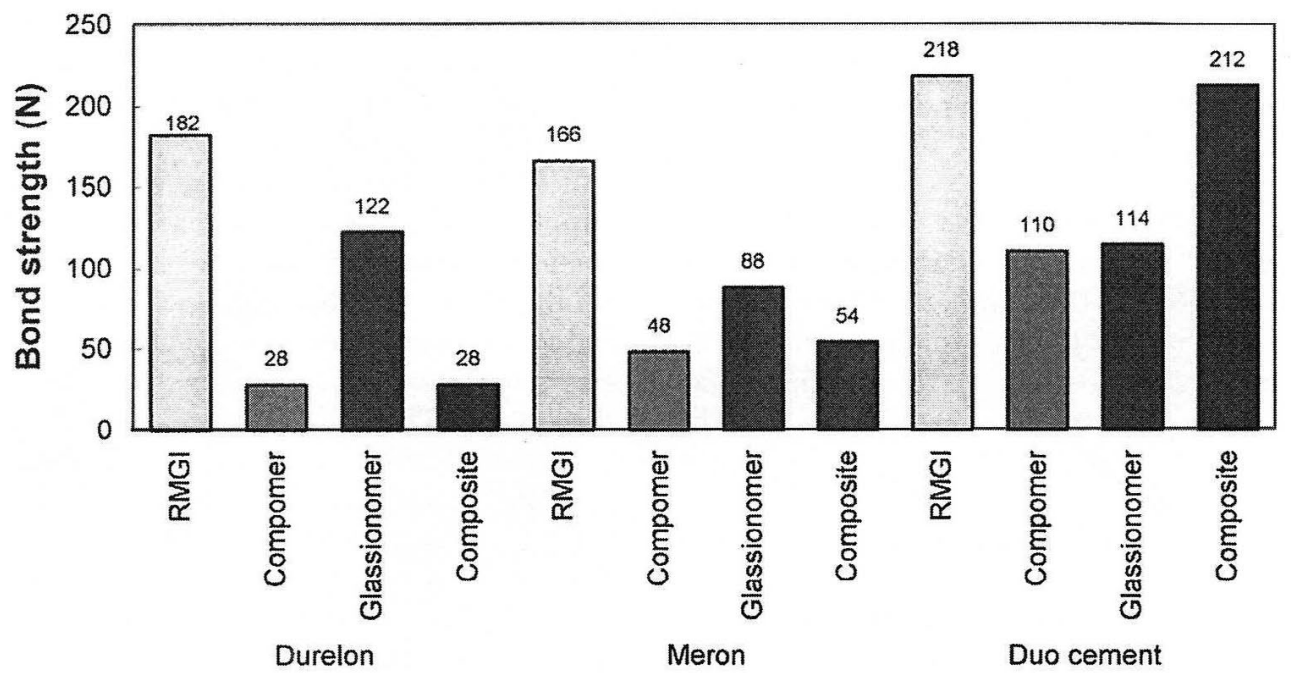

Fig The means bond strength values of tested core and cement materials.

After storage, the bond strength was measured with a Haunsfield tensometer (Haunsfield test equipment company, HTE 37 Fullerton Road Craydon, England) in a tensile mode at a crosshead speed of 5 $\mathrm{mm} / \mathrm{min}$.

Statistical evaluation was performed with univariate analysis of variance. Duncan's post hoc test was used for multiple comparisons of means.

\section{RESULTS}

Mean bond strength values were calculated. ANOVA revealed significant differences among groups $(\mathrm{p}<0.001)$. The types of cement and core materials 
were statistically different $(p<0.001)$. The interaction of cement and core was significant $(p<0.01)$.

Table 3 and 4 show Duncan's test results of cements and core materials. The Duo-Cement (resin cement) was statistically different from the other cements tested $(\mathrm{P}<0.001)$.

The strongest bond strength with resin modified glass ionomer cores was obtained with resin cement (Duo-Cement Kit) $(218 \mathrm{~N})$. The lowest bond strength values with composite and compomer cores were obtained with carboxylate cement (Durelon) (28 N) (Figure).

While the adhesive type of failure was observed in most of the samples, the cohesive failure type was rarely seen.

\section{DISCUSSION}

The dentist should consider the results of ongoing researches that involve bonding strengths of cements to core/tooth foundations before determining a preferable cement or core material ${ }^{4)}$.

A complete cast crown is made to restore a tooth that has an original contour and function after it sustains extensive damage from caries or fracture. Crown preparation is more difficult if the length of opposing axial walls is inadequate. This situation may be improved if a core is placed on the tooth before the crown is made ${ }^{4,5)}$.

The retention of the cast crown cemented to the teeth restored with core materials is critically important. In the present study, we found that a significant relationship existed between core materials and luting cements $(p<0.001)$. Different types of luting cements could produce different retentive strengths, and a comparison of luting agents leads to the conclusion that the resin cement has the most retentive values. In this study, the resin-luting cement exhibited the most retentive value with the resin modified glass ionomer, composite resin and compomer core materials. Juntavee and Millstein ${ }^{6)}$ also reported that resin luting agents were more retentive than glass ionomer luting ones for all core materials.

Al-Quoud et al. ${ }^{7)}$ stated that composite resin cores luted with polyurethane resin luting agents were the most retentive, and the glass ionomer-luting agent was generally less retentive than other luting agents. Arcoria et $a l^{8}{ }^{8}$ reported that the alloy-glass ionomer cores that were luted to cast gold crowns with glass ionomer cement exhibited higher bond strengths than the amalgam cores. In contrast, we observed that glass ionomer luting cement showed lower bond strength than the other luting cement regarding GIC core retention. This may be attributed to the utilization of conventional GIC in our study.

It was interesting that the RMGIC core material was the most favorable regarding cast retention in all-luting cement. However, Sindel et $a l .^{9)}$ reported that this material led to failure of all-ceramic crowns for its hygroscopic expansion when the materials were used for core build-up or adhesive bonding.

Important factors related to the success of a cast restoration are the design of the preparation of the supporting core and the accuracy of casting. In addition, Adhesion implies a first state of contact between adherent and adhesive mediated by physical and chemical interactions. The degree of spreading of a liquid on a surface is a measure of the wettability of the surface by a liquid, and it can be quantified by contact angle determination. In order to obtain high wettability, it is necessary that the surface energy of the substrate be higher than the surface tension of the adhesive. If the adhesive has high wettability, there will be intimate contact and adhesive efficiency will improve ${ }^{10,11)}$. The other factors include the nature of the core materials on which the casting is cemented, the luting agent and its biomechanical characteristics, and the degree of bond strength between the cement and core materials $^{1,12)}$.

\section{CONCLUSION}

Clinicians should take more consideration in the selection of a core material. Bond strength between core materials and cast retention is a critical factor for the success of a restoration.

The compatibility of different luting agents and core build up materials is an important factor. This in vitro study showed that the highest mean value with resin modified glass ionomer and composite resin cores was obtained with resin luting agent.

\section{ACKNOWLEDGEMENT}

Presented as a poster at the $27^{\text {th }}$ Annual Conference of the European Prosthodontic Association and $23^{\text {rd }}$ Annual Conference of the Swiss Society of Reconstuctive Dentistry, 4-6 September 2003, Central Medical Universitaire, Geneva, Switzerland.

\section{REFERENCES}

1) Chan KC, Azarbal P, Kerber PE. Bond strength of cements to crown bases. J Prosthet Dent 1981; 46: 297299.

2) Hormati AA, Denehy GE. Retention of cast crowns to amalgam and composite resin cores. J Prosthet Dent 1981; 45: 525-528

3) Millstein PL, Nathanson D. Effect of eugenol and and eugenol cements on cured composite resin. J Prosthet Dent 1983; 50: 211-215.

4) Dilt WE, Duncanson MG, Miranda JF, Brackett SE. Relative shear bond strengths of luting media with various core materials. J Prosthet Dent 1985; 53: 505508. 
5) Larson TD, Jensen JR. Microleakage of composite resin and amalgam core under complete cast crowns. J Prosthet Dent 1980; 44: 40-44.

6) Juntavee $\mathrm{N}$ and Millstein PL. Effect of surface roughness and cement space on crowr. retention $\mathrm{J}$ Prosthet Dent 1992; 68: 482-486.

7) Al-Quoud OA, Millstein P, Nathanson D. Effect of thermal cycling on retention of different cement-core material combination (Abstract). J Dent Res 1989; 68: 955.

8) Arcoria CJ, DeWald JP, Moody CR, Ferracane JL. A comparative study of the bond strengths of amalgam and alloy-glass ionomer cores. J Oral Rehabil 1989;
16(3): 301-307.

9) Sindel, J, Frankenberger R, Kramer N, Petschelt A. Crack formation of all-ceramic crowns dependent on different core build-up and luting materials. J Dent 1999; 27: 175-181.

10) Erickson RL. Surface interactions of dentin adhesive materials. Oper Dent 1992; Suppl. 5: 81-94.

11) Rosales-Leal JI, Osorio R, Holgado-Terriza JA, Cabrerizo-Vilchez MA, Toledano M. Dentin wetting by four adhesive systems. Dent Mater 2001; 76: 526-532.

12) Worley J, Hamm R, Von Fraunhofer J. Effect of cement on crown retention. J Prosthet Dent 1982; 48: 289-291. 